\title{
Identificando a branquidade inominada: corpo, raça e nação nas representações sobre Gisele Bündchen na Mídia Transnacional*
}

Suzana Maia**

\section{Resumo}

Este artigo examina as configurações discursivas que associam o corpo da top model Gisele Bündchen ao corpo da nação brasileira, $e$ analisa as formas como essas configurações definem o que significa ser brasileira/o de acordo com os discursos presentes nas mídias brasileira e transnacional. Para tanto, utilizo imagens de Gisele a fim de interrogar as formações raciais em um e outro contexto, e de examinar como tais formações têm se reconfigurado a partir das recentes mudanças demográficas $e$ políticas nos contextos brasileiro e estadunidense. Alinho-me, nesse sentido, aos estudos sobre relações raciais, adotando aqui a perspectiva desenvolvida pelos estudos críticos sobre branquidade.

Palavras-chave: Branquidade, Relações Raciais, Representações.

\footnotetext{
* Recebido para publicação em 13 de setembro de 2010, aceito em 04 de abril de 2011.

** Professora Adjunta I da Universidade Federal do Recôncavo da Bahia, PesquisadoraCNPq.MaiaSuz@gmail.com
}

cadernos pagu (38), janeiro-junho de 2012:309-341. 
Identifying the un-Named Whiteness: race, body, and nation in representations of Gisele Bündchen in the transnational media

\begin{abstract}
This article examines the discursive configurations that associate the body of top model Gisele Bündchen to the body of the Brazilian nation, and analyses the ways through which these configurations define what means to be Brazilian according to discourses that circulate in Brazilian and transnational media. In order to do that, I use images of Gisele to interrogate the racial formations in the two contexts and to examine how theses formations are being reconfigured due to recent changes in the demographic and political contexts in Brazil and in the United States. Following the studies of racial relations in the two countries, I adopt a framework developed by the studies that focus on the construction of whiteness.
\end{abstract}

Key Words: Whiteness, Racial Relations, Representations. 
Em um comentário sobre o sucesso da moda brasileira, o New York Times (01/08/2000) atribui crédito a top model Gisele Bündchen por chamar a atenção ao Brasil $e$ ao que significa ser brasileiro/a. Ela e suas "colegas brasileiras" (outras modelos) são sistematicamente associadas pelo Times a qualidades que evocam características classificadas, simultaneamente, como "bi-raciais" $e$ "globalizadas". No Brasil, por sua vez, onde Gisele se transformou numa espécie de ícone nacional, seu corpo e imagem são considerados como produtos de exportação de máxima qualidade e como representante da nação em arenas transnacionais. Tanto na mídia brasileira como na estrangeira, Gisele é apresentada como o novo ideal "universal" de beleza. Observe-se que Gisele Bündchen, uma das mais, se não a mais, famosa modelo de moda de todo o mundo desde a virada do século XXI, é uma mulher de quase dois metros de altura, de cabelos castanhos claros com mechas aloiradas, olhos azuis e pele clara, nascida no Rio Grande do Sul. Como pode Gisele, pertencente a uma família de descendentes de alemães do sul do Brasil ser considerada "biracial" pela mídia estadunidense? E como pode ser ela considerada a representante da nação pela mídia brasileira, num país em que a mistura racial foi historicamente construída como ideologia oficial?

Nos Estados Unidos e no Brasil, imagens midiáticas evocam formas de pertencimento nacional que foram moldadas ao longo de uma história de encontros coloniais e neo ou pós-coloniais. Nesses encontros, diferentes partes do mundo são imaginadas de acordo com representações coletivas, que associam maneiras de lidar com o corpo a espaços geopolíticos específicos (McClintock, 1995; Stoler, 1995). Mulheres brasileiras, através da história, têm sido representadas como "misturadas", uma visão que lhes empresta uma qualidade ao mesmo tempo racializada $e$ sexualizada numa arena global. Assim como em outros países da América Latina, a confluência entre corpo $e$ nação $e$ a rearticulação de teorias racialistas - tal como na construção da ideologia de democracia racial - foi de fundamental importância 
na definição do Brasil enquanto nação soberana em momentos cruciais da sua história (Parker, 1991; Piscitelli, 2004; Maia, 2009; Pinho, 2004; Sommer, 1990; Stolke, 2006). No presente contexto, representações sobre a mulher brasileira continuam difundidas em discursos $e$ imagens em que raça, corpo e nação se encontram inter-relacionados. Tais representações aparecem de diversos modos com diferentes significados em cada contexto específico.

Neste artigo, busco analisar as configurações discursivas que associam o corpo de Gisele Bündchen ao corpo da nação brasileira, e examinar como essas configurações definem o que significa ser brasileira/o de acordo com os discursos presentes nas mídias brasileira e transnacional. Para tanto, utilizo imagens de Gisele a fim de interrogar as formações raciais em um e outro contexto, e de examinar como tais formações têm se reconfigurado a partir das recentes mudanças demográficas $e$ políticas nos contextos brasileiro e estadunidense. Alinho-me, nesse sentido, aos estudos sobre relações raciais, embora adotando aqui um ângulo um tanto diferente daqueles tradicionalmente desenvolvidos nas ciências sociais.

$\mathrm{Na}$ maior parte dos estudos de "relações" ou "formações" raciais, o foco recai sobre o negro como um problema. Extensa é a literatura produzida nos Estados Unidos e no Brasil, retratando minuciosamente as práticas religiosas e formação de identidade negra, o índice de desigualdade socioeconômica e política entre negros e brancos, assim como posteriormente, o movimento negro $e$, correntemente, os efeitos das ações afirmativas sob a realidade do estudante e profissional negro. Nessa literatura, mesmo que invariavelmente presente, o branco se constitui num sujeito quase invisível, não questionado, não "desmascarado" na sua hegemonia pretensa e silenciosa de si mesmo como um problema.

Nos Estados Unidos, esse silêncio em torno da branquidade como tema começou a ser questionado na década de 1990. Entre os primeiros deslocamentos que contribuíram para essa mudança de perspectiva, podemos citar a luta pelos direitos civis e a entrada dos negros nas universidades, como nos mostra Frankenberg 
(1995), em pioneiro estudo sobre branquidade no contexto do movimento feminista americano. Questionado por suas companheiras negras, Frankenberg pesquisa sua posição de privilégio na hierarquia social definida pela raça, tal como delineada no contexto estadunidense. Outros estudos pioneiros sobre branquidade nos Estados Unidos nos mostram como a identidade branca estadunidense se deu a partir da aglomeração de várias identidades étnicas europeias, tais como judeus, italianos e irlandeses, numa categoria racial inclusiva "branca" (Brodkin, 1998; Roediger, 1991). Essa aglomeração étnica, segundo diversos autores, se deu por seu afastamento estratégico da população negra que, naquele momento (1940-50), imigrava massivamente em direção ao norte industrializado. Nos últimos anos, tem havido uma profusão de estudos nos Estados Unidos que investigam a formação de grupos que defendem a supremacia branca, a construção da identidade branca nas escolas e nas práticas adotivas, as representações de beleza branca no cinema, assim como o significado da branquidade entre populações de imigrantes, entre outros aspectos. ${ }^{1} \mathrm{O}$ que todos esses estudos têm em comum é o interesse em tornar visíveis padrões de racismo, centrando sua atenção naquelas camadas mais privilegiadas da população, quase que invariavelmente de cor de pele mais clara, $e$ de origem ou ascendência europeias.

No Brasil, apesar de uma extensa e profícua literatura a respeito das "relações raciais", o foco sobre o negro ainda continua sendo a regra. Apenas recentemente, alguns estudos tentaram modificar essa tendência ${ }^{2}$, e, deduzindo-se do diminuto

\footnotetext{
1 Para um panorama do que se tem produzido nesse campo de estudos, conferir, por exemplo, coletâneas organizadas por Frankenberg, 1997; e Doane e BonillaSilva, 2003.

2 Dentre os estudos mais antigos, pode-se citar o trabalho de Guerreiro Ramos (1957), enquanto, na literatura recente, duas coletâneas se destacam: uma organizada por Vron Ware (2004), e outra, no campo da psicologia social, organizada por Carone e Bento (2002). O estudo de Hofbauer (2006) sobre a construção histórica da branquidade, assim como os trabalhos de Piza $e$
} 
número de artigos publicados sobre o tema, os estudos sobre a branquidade parecem ainda sofrer certa resistência por parte daqueles interessados em compreender as relações raciais no Brasil. Em outras palavras, age-se como se fosse possível entender o racismo sem entender suas várias manifestações, dentre as quais as que definem um projeto hegemônico de branquidade, perpetuando assim a percepção do racismo como um problema do negro, e não um problema do branco. Como Ware (2004) ressalta, os estudos raciais e os movimentos negros no Brasil há tempo tentam desmascarar o mito de democracia racial, revelando como as representações sobre os negros são pejorativas e perpetuam o preconceito. No entanto, têm feito muito pouco para desvendar as formas como o racismo é perpetuado através das representações narcisistas do branco sobre o seu próprio grupo social. ${ }^{3} \mathrm{~A}$ branquidade, invariavelmente associada ao prestígio social, econômico e político, ainda se apresenta como a norma transparente.

Uma grande dificuldade que os estudos de branquidade enfrentam no Brasil decorre da percepção e discursos advindos das camadas mais privilegiadas da população de que "aqui ninguém é branco", como nos mostra Liv Sovik (2004). No Brasil, a persistente ideologia da democracia racial faz com que a branquidade como tal seja muito raramente evocada enquanto categoria social. Ao contrário, as elites e classes médias do país compreendem a si mesmo como sendo o resultado criativo da real ou simbólica miscigenação entre as três "raças" fundadoras da nação: o branco, o negro e o índio. É comum no Brasil o discurso de que, em consequência da histórica miscigenação da população brasileira, a elite teria sempre "um pé na cozinha", o que tornaria sua branquidade algo maleável e transparente o suficiente para não reconhecer a responsabilidade que lhe cabe na perpetuação

Damasceno - numa coletânea organizada por Guimarães (2000) - também oferecem valorosas contribuições nesse sentido.

${ }^{3}$ Conferir coletânea organizada por Ramos (2002) sobre racismo na mídia brasileira. 
de profundas desigualdades sociais, definidas de acordo com cor de pele/raça. No entanto, essa transparência é apenas pretensa $e$ superficial. Através de um deslocamento do olhar em que o negro cessa de ser apresentado como um problema e em que a branquidade se transforma no objeto de escrutínio, as marcas do ser branco se tornam passíveis de serem desveladas. Pois, apesar de a branquidade continuar inominada, seus atributos associados ao lugar estrutural de privilégio ocupados por pessoas de cor de pele mais clara e de origem europeia - aparecem de maneira inequívoca.

Neste artigo, examino os valores, percepções e imagens da branquidade que circulam na mídia transacional, através dos quais a supremacia de ideais brancos de origem europeia é promovida. Num contexto em que a branquidade não ousa enunciar seu próprio nome, devemos atentar para as metáforas e eufemismos pelos quais se traduz, e através dos quais o racismo penetra a estrutura psíquica dos indivíduos, atingindo formas inconscientes, ou quase inconscientes, de representações, ou seja, na definição mesma de sensibilidades estéticas.

Este artigo foi elaborado em dois momentos distintos. A primeira parte se constituiu originalmente numa apresentação oral para um congresso sobre cultura popular ocorrido em Massachusetts em 2002. Naquele momento, pesquisei de forma mais ou menos aleatória as representações sobre Gisele que se me apareciam de modo insistente na mídia. Certamente em decorrência de uma nacionalidade compartilhada, as imagens de Gisele não podiam deixar de me chamar atenção toda vez que parava numa loja de revistas ou navegava por notícias de internet, ou quando passava em frente às grandes vitrines da Victoria Secret - famosa marca de lingerie -, onde as imagens de Gisele, ocupando dois andares de loja, dominavam o cenário. Intrigavame, então, o fato de uma beleza estrangeira, tida como exótica, ter se tornado um ícone de beleza estadunidense.

A segunda parte do artigo corresponde às representações sobre Gisele que aparecem na mídia brasileira. Tantas e tão 
profícuas são essas imagens nas revistas nacionais, que optei por examinar mais detidamente as representações que aparecem na revista Veja. ${ }^{4}$ Essa opção se deve ao fato de ser essa a revista de maior circulação nacional, com uma distribuição que ultrapassa a casa de um milhão de exemplares vendidos semanalmente. Outra razão para a escolha está relacionada ao fato de a revista Veja representar parcelas significativas das classes médias e elites do país, alvo do objeto de estudo deste artigo, por se espelharem nas imagens de branquidade tal como expressas por Gisele Bündchen. As representações aqui analisadas apontam para as complexas intersecções entre gênero, raça e classe, historicamente constituídas no encontro entre nações, e que ressoam no modelo contemporâneo de branquidade, cujas referências, como eu espero demonstrar, atravessam as fronteiras de diferentes Estados-nação.

\section{Gisele no contexto transnacional e estadunidense}

Numa matéria de agosto de 1999, "Hot Model: Gisele", a revista Rolling Stone enfatiza, além dos seios de Gisele e seu "sex appeal", a narrativa de uma garota pobre, que cresceu numa pequena vila, e que foi "descoberta" por um agente de modas ainda com quatorze anos (ou quinze, de acordo com outras fontes), quando, numa viagem a São Paulo, fazia um lanche num McDonalds. Enquanto alguns afirmam que essa era uma viagem de escola, outros dizem que ela já estava sendo treinada nas escolas de passarela em sua cidade natal e que, na realidade, se encontrava em São Paulo para um desfile de modas. Se Gisele estava simplesmente passeando com colegas num shopping center, ou se estava comendo um hambúrguer no McDonalds também é fonte de controvérsia.

4 Esta pesquisa contou com a ajuda da estudante de curso secundário do Colégio Estadual Nilton Sucupira, Sinara Pereira de Jesus, que realizou pesquisa sobre as imagens de Gisele Bündchen na Revista Veja, publicadas de 1999 a 2008. 
Estes se constituem em detalhes importantes na construção do sonho americano de ascensão social, pois seguem outros mitos comuns à narrativa de "top models", como Alek Wek, por exemplo, também "descoberta" num McDonalds onde trabalhava em seu país de origem, o Sudão. Com efeito, de acordo com o "The Atlanta Journal" num artigo de fevereiro de 2000, Alek Wek é considerada uma pioneira para modelos de outras partes do mundo, não só por quebrar barreiras de cor, como também por quebrar barreiras de padrões de beleza. Entre o que o "Atlanta" descreve como "coal-black skin" - pele negra como carvão -, e os cabelos de Alek Wek - completamente raspados naquele momento -, e os cabelos longos e aloirados de Gisele há diferenças significativas. No entanto, o que o "Atlanta" sugere é que a cena fashion tem se tornado mais tolerante em relação a "aparências exóticas". Mas quão exótica pode Gisele ser considerada? Quais os critérios e idiomas que expressam sua qualidade de exótica? Como esse suposto exotismo está conectado ao fato de ela ser brasileira e o que isto tem a ver com a configuração racial estadunidense?

De acordo com D’Avila (2001), na medida em que há previsão de que "Hispânicos" ou "Latinos" irão se tornar a maior categoria étnico-racial no mercado estadunidense, eles também passam a ocupar posições estratégicas dentro da indústria publicitária naquele país. Em seu trabalho a respeito da mídia latina nos Estados Unidos, D'Avila demonstra como a presença de profissionais latinos nos meios de comunicação tem funcionado no sentido da desconstrução dos estereótipos latinos presentes em propagandas publicitárias. O lado irônico desse processo, como demonstra a autora, é que as imagens de latinos têm se tornado cada vez mais embranquecidas no intuito de questionar o latino "escuro", que passa a ser visto como apenas um estereótipo de uma realidade latino-americana muito mais diversificada em termos de raça e classe.

Se o corpo de Gisele, assim como o corpo da nação brasileira, pode ser equacionado às imagens do corpo latino ou 
hispânico - mesmo admitindo-se uma visão embranquecida dele não está claro. A especificidade linguística e as divisões de raça $e$ classe entre os vários grupos de nacionalidade presentes nos Estados Unidos necessitam de um rigor analítico renovado no caso da presença brasileira. Em nenhuma das fontes de mídia analisadas, a imagem de Gisele foi associada diretamente ao termo latino ou hispânico. No entanto, isso não significa que qualidades seletivas que são associadas à latinidade (particularmente à da mulher latina), ao lado de outras mais próximas à branquidade (ainda que adaptada aos trópicos), não sejam utilizadas como uma expressão de sua "autenticidade" e sucesso.

Em quase todos os artigos analisados, aparecem, aqui e ali, atributos como "natural" e "saudável", caracterizando Gisele; qualidades que associam seu corpo a espaços geopolíticos presumidamente ligados a uma natureza mais selvagem, como a América Latina. Ainda em setembro de 2000, o New York Times anuncia, contrastivamente, o fim de uma era em que modelos de aparência doentia (bulímicas ou anoréxicas) eram comuns. Segundo o Times, o mercado de moda foi simplesmente "cultivado" pelo saudável corpo de Gisele e de outras modelos brasileiras. Esses atributos devem ser entendidos como uma reação a um momento da indústria de moda, caracterizado pelo aparecimento das fotos de Kate Moss, especialmente aquelas divulgadas pela Calvin Klein em meados dos anos de 1990, que lançaram o estilo "heroína chic" e o corpo anoréxico e frágil como modelo. Naquele momento, círculos feministas e médicos acusavam a indústria da moda de fomentar tanto o uso de drogas como a heroína quanto os distúrbios de alimentação como bulimia e anorexia, que tiveram então uma grande incidência (Bordo, 1997). Se Gisele representa uma imagem mais próxima a uma suposta "normalidade" é também questionado por feministas. ${ }^{5}$ No entanto, foi assim que Gisele foi apresentada ao grande público. Em outubro de 1999, o Times de Londres

${ }^{5}$ Ver artigo de Shane Watson in The Guardian Jan 28, 2000. 
descreve Gisele literalmente como uma substituta do corpo anoréxico, e acentua a dificuldade de Gisele, no início de sua carreira, em encontrar trabalho devido ao modelo predominante de magreza exagerada, ao qual ela supostamente não corresponderia. E é de Gisele a seguinte afirmação:

Eu não podia mudar para eles, cortar meu cabelo, mudar minha cor, eu era normal e eles tinham que me aceitar assim (I couldn't change for them, cut my hair, change my color - I was normal and they had to take me as I was) (The Times, 2/10/1999; tradução e ênfase da autora).

Aqui podemos observar o deslize na fala de Gisele que associa diretamente cor (de pele), cabelo e uma suposta "normalidade" ligada a seu lugar social e de origem. De fato, o sucesso de Gisele Bündchen é entendido não apenas como o resultado de seus atributos físicos, mas de uma combinação de "personalidade, beleza e corpo", como expresso pelo vicepresidente da mundialmente famosa agência de modelos Elite, Massimo Redaelli. Redaelli lamentou publicamente a perda de Gisele quando esta abandonou a agência Elite em favor da IMG, em 1997, mas comentou que ele já tinha seus olhos atentos para o "corpo exótico" das brasileiras, quando ele contratou uma nova secretária, fluente em português. De acordo com um artigo do Boston Globe (abril, 2000), as melhores agências do mundo estão voltadas para o Brasil na busca do "next big face" (próximo rosto famoso). Porém, não para a totalidade do Brasil, e sim, para as "descendentes de imigrantes alemães, com pernas longas, e que se estabeleceram no sul do país". Dentre as razões para justificar esta tendência geográfica na indústria da moda, o diretor da Elite no Brasil menciona o "melting pot" brasileiro (mistura brasileira), capaz de produzir "faces globalizadas", mas que possuam "menos traços de estereótipos étnicos". Através dessas representações, podemos ler como uma estética embranquecida, coincidente com o que é encontrado nas elites transnacionais, é equacionada com 
uma estética "globalizada", epifenômeno do colonialismo universalista. Apenas membros seletos de outras nações ou "raças", aqueles em que as marcas "étnicas" podem ser obliteradas, são passíveis de ser incorporados numa mistura simbólica, ainda que provisória e ambiguamente definida.

As formas com que as qualidades de Gisele e de outras modelos brasileiras correspondem, ou contradizem imagens do Brasil, enquanto nação, refletem a ambiguidade com que questões de raça são transnacionalmente concebidas. Em algumas das fontes midiáticas analisadas, as qualidades do corpo de Gisele são diretamente associadas a traços positivos do Brasil. O jornal inglês The Guardian (1999), por exemplo, anuncia que "the full-bodied Amazons", as "corpulentas Amazonas", estão "colonizando" a cena fashion do hemisfério norte, ao lado de músicos, designers, e a "imagem romântica de uma nação vasta, apaixonada, preguiçosa, multicultural, e sexualmente carregada". Já o designer brasileiro Fause Haten, na mesma matéria, comenta: "As pessoas querem o que o Brasil tem, é felicidade. Tudo o que as pessoas acham a nosso respeito está ligado à felicidade - futebol, carnaval, samba, praias. Nossas mulheres emanam saúde". Mais adiante, porém, o mesmo artigo chama a atenção para o fato de que apenas uma modelo é "of mixed-race" (ou racialmente misturada), num país que tem a maior população negra fora da África, e afirma que a cena fashion não reflete a realidade do Brasil. Aqui, como em outros lugares, Gisele é ao mesmo tempo vista como típica e como exceção.

Num artigo de dez páginas que a revista Rolling Stone (14/09/2000) dedicou a Gisele Bündchen, ela é apresentada tendo como pano de fundo uma realidade brasileira da qual parece ter escapado. Para a construção da matéria, o repórter Kirk Gaard acompanha Gisele numa viagem ao Brasil, onde ela irá participar de um desfile de modas. São Paulo é representado como:

muito parecido com um grande esgoto. As crianças nas ruas não têm sapatos e seus pais vivem em restos esfarrapados 
em que se abrigam. Todos tossem com a terrivel fumaça dos carros hediondos (Rolling Stone 14/09/2000).

[tradução da autora]

Separado deste caos, Kirk Gaard conversa com Gisele no conforto de uma limusine, onde ela acende seu cigarro e fala com sua voz brasileira "gutural". A ambiguidade da equação entre o corpo de Gisele e a nação brasileira está também expressa no New York Times, em dois artigos publicados em 2000. Em agosto, Gisele é considerada responsável por chamar a atenção para tudo que é brasileiro, desde a caipirinha aos minúsculos biquínis brasileiros, que ganharam popularidade nos Estados Unidos. No entanto, de acordo com o mesmo artigo, apesar de ser um lugar "da moda", o Brasil ainda precisa quebrar o padrão de exploração de mão-deobra barata. Em novembro desse mesmo ano, o Times reporta o encontro de Gisele com o então presidente do Brasil, Fernando Henrique Cardoso, numa reunião internacional sobre a indústria têxtil brasileira. Tal encontro com o presidente foi também amplamente divulgado no Brasil, consolidando Gisele como um novo ícone de brasilidade.

\section{Gisele e os atributos da branquidade na mídia brasileira}

Vistas na passarela, deslizando sobre pernas intermináveis, elas parecem todas iguais. Altíssimas, magérrimas, cabelo liso

e comprido, a beleza inacessível de seres de uma raça mutante. Mas, na hora de escolher as modelos para apresentar tais coleções, as grifes de Paris, Milão, Londres e

NY cada vez mais convocam meninas com um diferencial: são brasileiras. (...) Em comum, elas têm o inglês macarrônico, a mamãe do lado, um endereço em NY e a sensualidade - esta, a mais citada justificativa para o propalado sucesso das brasileiras lá fora. (...) Sensualidade de modelo, é claro, nada que evoque o estilo das dançarinas de axé e congêneres (Veja 05/07/2000, ênfase da autora). 
Desde 1999 quando, recém-saída de Horizontina e com passagem pelas passarelas de Nova York, Gisele aparece como modelo do ano na capa da Vogue francesa, ela não cessa de aparecer na mídia brasileira. No artigo "Pelé, Senna e agora Gisele" para a seção "Especial" da Veja, de 01 de dezembro de 1999, a repórter Ângela Pimenta constrói, como o fazem outros artigos internacionais, a narrativa de sucesso da gaúcha de 19 anos que se tornou "a mais requisitada modelo do milionário mundo da moda". Usando as referências e uma linguagem comum àquelas analisadas na seção anterior, Gisele aparece carregando seu cachorrinho Vida enquanto conversa com a repórter. Seu corpo e suas maneiras de comer e se comportar é contrastado com Kate Moss, um dos grandes ícones do mundo da moda, e que havia recentemente saído de uma clínica de reabilitação para dependentes químicos. ${ }^{6}$ Várias celebridades da moda nacional $e$ internacional foram citadas, atestando o inquestionável espaço ocupado por Gisele no panteão das "supermodels" 7 deidades máximas da sociedade de consumo e mídia. Nesse mesmo artigo, a mundialmente famosa estilista italiana - $e$ uma das proprietárias da grife Versace -, Donatella Versace, afirma que "Gisele é hoje a modelo ideal para nós. Ela infunde vida às roupas, tornando-as sexy e fortes". Carlos Mielli, proprietário da M. Officer no Brasil, por sua vez, diz que Gisele "é pontual como os britânicos, eficiente como os americanos, e criativa como os brasileiros". Já Sally Singer, da Vogue americana, diz que Gisele "encarna à perfeição o tipo de beleza do novo milênio".

Em março do ano seguinte, a Veja (22/03/2000) publica outro longo artigo em que Gisele é o centro da atenção. Em "As gaúchas são demais... como o Rio Grande do Sul se tornou uma

6 Como discutido na seção anterior, Kate Moss ficou conhecida pela campanha que realizou para a grife Calvin Klein, quando muitas de suas imagens foram associadas ao que ficou conhecido à época como o estilo "heroína chic", o corpo frágil, e anoréxico, associado às classes mais altas.

7 Enfatizando a origem alemã de Gisele Bündchen, posteriormente a mídia brasileira passará a tratá-la como "ubber-model". 
máquina de produzir top models", Rodrigo da Cunha se pergunta o porquê do desproporcional número de gaúchas no mundo da alta moda mundial. Algumas das razões por ele aventadas são:

A primeira é que o padrão internacional de beleza mais
aceito hoje se encaixa como uma luva nas características
físicas das mulheres dos pampas. Nos editoriais da moda e
nas passarelas domina o estilo europeu de mulheres com
quase 1,80 de altura, pele clara e olhos azuis verdes. E isso
não falta no Rio Grande do Sul, estado onde a população é
formada por descendentes de imigrantes alemães, italianos
e poloneses. Outro fator que explica a proliferação de
modelos do Rio Grande do Sul é a determinação.
Geralmente advindas de famílias humildes e sem muitas
perspectivas de crescimento na vida, elas se inspiram nos
exemplos de sucesso e tomam a carreira de modelo como
um norte na vida profissional. Diferente de outras modelos
elas não fazem frescuras ou biquinhos... As gaúchas vêm
para vencer (Veja $22 / 03 / 2000$, ênfase da autora).

Dois elementos que aparecem nesse artigo são fundamentais para o entendimento da ideologia através da qual raça é entendida no contexto brasileiro: o "estilo europeu" e a "determinação". Esses elementos aparecem aqui como noções independentes, embora necessários para o sucesso dessas mulheres na cena fashion internacional. Vamos começar pelo primeiro deles, a determinação, que denota o mérito individual dessas mulheres. A meritocracia ${ }^{8}$ - desenvolvida no âmbito do modelo individualista ocidental -, é uma perspectiva de acordo com a qual o indivíduo ocupa uma determinada posição na hierarquia social devido ao seu próprio mérito, ou vontade e capacidade individuais. Tal perspectiva negligencia a relação dos indivíduos com seu grupo social, e torna apenas coincidente o fato

8 Ver Guimarães (1999) para discussão sobre os pressupostos filosóficos do conceito de meritocracia, e como este se insere nos debates contemporâneos sobre ações afirmativas. 
de estas serem mulheres do sul e sua suposta "determinação". Se entendermos, porém, "determinação" como um eufemismo para vantagem inicial - ou seja, o privilégio que o ser branca e do sul do país lhes confere numa arena nacional e transnacional -, veremos que seu "mérito" se dá, nesse caso, mais pelas origens sociais do que qualquer coisa que emane da vontade ou capacidade especial de determinados indivíduos e não de outros.

Como demonstrado através dos estudos críticos de branquidade, a hiper valorização discursiva da branquidade é uma das formas com que a supremacia branca perpetua o racismo sem que se diga o seu nome. A própria localização, dentro da organização editorial da revista, revela como negros e brancos são segregados no espaço discursivo. As imagens de Gisele aparecem apenas nas seções de Gente, Moda, Especial e Comportamento, espaços destinados apenas aos famosos que, não coincidentemente, são quase todos brancos. Nesses espaços, reservados principalmente para "entreter" mais do que "informar" o público, pele clara e cabelos "sedosos" - mesmo quando decorrentes de tratamentos cosméticos - são predominantes.

No entanto, como nos chamam a atenção os estudos sobre a mídia, essas duas esferas de informação - entretenimento $e$ notícia - não são independentes. Ao entreter, a mídia passa incessantemente informações fundamentais para a construção dos valores e comportamento social. Assim, "notícias de entretenimento" funcionariam como um código através do qual mensagens tabus, como o preconceito, o classismo, e o racismo, são sub-repticiamente passadas. A super valorização de Gisele e dos atributos de seu corpo aparecem incessantemente na Veja, em mensagens em que noções de raça estão persistentemente presentes. Embora usando por vezes a linguagem do mérito pessoal, essas mensagens racializadas remetem inequivocamente à sua posição de privilégio enquanto originária do sul do país e, portanto, de descendência e "estilo" europeus.

Em outra matéria, de janeiro de 2004, na seção "Especial" da Veja, a jornalista Daniela Pinheiro escreve sobre os atributos 
que tornam uma pessoa "sexy". Com uma foto de Gisele ocupando toda a página da manchete, a autora discorre sobre as últimas descobertas realizadas pelos principais centros "científicos" do mundo. Pinheiro argumenta a existência de tendências universais de atração sexual que podem ser detectadas cientificamente. Para defender seu ponto de vista, realiza um compêndio de "respeitadas publicações" internacionais como New Scientist, The Lancet e Nature, que "provam" que uma série de variáveis e critérios pode ser "universalmente" definida. Tornando de validade universal as pesquisas realizadas em lugares como Inglaterra, Alemanha, Canadá, Austrália e Hong Kong, a jornalista da Veja antevê a possibilidade de traçar um "perfil aproximado" do tipo universalmente ideal.

Para o homem, de acordo com as pesquisas citadas, o ideal seria ter voz grossa, ser socialmente cobiçado, fazer ginástica $e$ possuir um cheiro que lembraria o do pai da admiradora. $\mathrm{O}$ fato de exercitar-se por si só já o faria desejável, e sua voz grossa revelaria uma característica dos homens mais fortes e, por estranho que isso possa parecer, também dos mais cabeludos. Para a mulher, o ideal é que tenha traços infantis, corpo curvilíneo, lábios grossos, olhos grandes e arredondados, testa larga, nariz e queixo pequenos, e maçãs do rosto acentuadas. Traduzindo tais ideais em personalidades conhecidas, o artigo identifica os rostos de Kate Moss, Brigitte Bardot e Carolina Dieckmann como representativos. Em relação ao corpo, uma pesquisa suíça aponta a Vênus grega como o modelo ideal de beleza. Os quadris mais largos que a cintura e uma proporcionalidade entre os membros seriam encontrados, por exemplo, em Fernanda Lima ou Danielle Winits. O rosto de Gisele, por sua vez, se enquadraria no modelo de perfeição "descoberto" por um centro de pesquisa australiano, deduzido de um cálculo de precisão definido por ninguém menos que o matemático Pitágoras, e que incluiria a proporção entre a largura da boca e a do nariz. 
Ao final, a repórter Pinheiro, contrariamente ao que defende no decorrer do artigo, reconhece não haver padrão universal absoluto de beleza e cita a diversidade de ideais relacionados à grande diversidade étnica e cultural do planeta. Não obstante, a importância de tais "descobertas científicas", segundo ela, é que estas apontariam o que "uma maioria expressiva" da população tem como padrão, ajudando o leigo leitor a compreender o "comportamento humano". Utilizando-se de teorias evolucionistas que defendem o imperativo biológico como critério de atração sexual entre pares, a Veja equaciona europeidade, beleza e saúde reprodutiva, ao tempo em que naturaliza como "universal" uma sensibilidade estética tal como definida por uma herança colonial racista. Através do eufemismo e metáfora do belo, a revista acaba por valorizar positivamente a estrutura psíquica colonialista, associando os atributos necessários à atração sexual a uma suposta superioridade europeia, sem nunca mencionar explicitamente a branquidade. Não parece ocorrer à autora a relação entre beleza, tal como definida, e privilégio. Tornando o conceito de visibilidade auto-evidente e, por isso, inquestionável, a autora afirma: "É que o conjunto é 'visivelmente' mais harmônico". Visível para quem e sob que ângulo?

$\mathrm{Na}$ Veja, como nas mídias transnacionais, as imagens de Gisele se multiplicam, quase que semanalmente, acompanhando sua trajetória estrelar. Seu apartamento no bairro de Tribeca, em Nova York, seus hábitos alimentares, seu salário a cada desfile, as diversas campanhas publicitárias em diversas partes do mundo, as festas e os restaurantes que frequenta, suas visitas ao Brasil e sua família são assuntos exaustivamente explorados. Além destes, um dos assuntos mais comentados sobre Gisele são suas relações afetivas. Seu namoro com o famoso ator hollywoodiano Leonardo DiCaprio, entre 2002 e 2005, lhe renderam presença constante tanto na mídia brasileira quanto na euro-estadunidense. Seus distanciamentos e reaproximações, suas viagens, as roupas que vestiram na entrega do Oscar 2005 e em outros eventos midiáticos, assim como a conta bancária de ambos, são 
amplamente divulgados. A relação que, segundo a Veja, se definia mais como um "ficar" do que um compromisso sério foi rompida em 2005, quando Gisele passa a "ficar" com uma variedade de parceiros, todos eles parte da elite mundial. O surfista Kelly Slater, o milionário e socialite Ricardinho Mansur, o ator Rodrigo Santoro, e o único negro, o famoso pop star do rock, Lenny Kravitz, estão na lista que a Veja cita para uma Gisele que aparece como boêmia, independente e curtidora das noitadas cariocas e novaiorquinas.

No final de 2006, no entanto, essa imagem começa a mudar e Gisele começa a aparecer novamente como referida no início de sua carreira, ou seja, como uma "moça de família". Essa mudança se dá particularmente devido à sua relação com Tom Brady, jogador de futebol americano e ícone cultural naquele país. Nascido na Califórnia e graduado pela Universidade de Michigan, Tom Brady é jogador do New England Patriots, time de futebol associado à elite bostoniana, uma das mais "brancas" e "puras" do país. Já durante o namoro, Gisele aparece frequentemente ao lado de Brady e de seu filho ${ }^{9}$, na praia, no parque, correndo $e$ indo ao shopping, e, numa das fotos mais divulgadas pela imprensa, na noite de abertura da exposição anual de moda no Metropolitan Museum of Art. Vestida num longo Versace $e$ acompanhada de um ídolo das elites americanas, Gisele parece ter entrado definitivamente na branquidade, definida nos termos estadunidenses e transnacionais. Uma branquidade, se assim podemos definir, mais "branca" e compatível apenas com aquela encontrada no sul do Brasil. Sua incorporação na branquidade se consolida ainda mais com seu casamento com Tom Brady, com quem posteriormente tem um filho, fixando residência numa mansão em Beverly Hills.

9 Embora a ex-namorada de Brady, Brigite Moynhan, tenha tido um filho seu quando ele já estava se relacionando com Gisele, esse fato não parece ter causado muita sensação na mídia, preservando a "respeitabilidade" das partes envolvidas. 
Em nenhuma das imagens e discursos sobre Gisele Bündchen na Veja, a linguagem da mistura e da miscigenação tão característica da identidade brasileira presente em discursos nacionalistas -, se faz presente. Como dito pela Veja no artigo citado no início dessa seção, é como se a sensualidade que faz com que Gisele seja "universalmente" desejada fosse bem diferente daquela que caracteriza as dançarinas de axé, que se encontram majoritariamente na parte mais norte do país, não coincidentemente, mais negra ou miscigenada. A insistência da Veja em ressaltar os atributos de Gisele e relacioná-los à sua origem social sulista e sua ascendência alemã deixa-nos entrever o conteúdo racialista e racista através do qual a branquidade se perpetua.

\section{Compreendendo os discursos sobre Gisele no Brasil e Estados Unidos: um esboço de análise comparativa de duas formações raciais}

Historicamente, os sistemas raciais do Brasil e dos Estados Unidos foram vistos como opostos e contrastantes. Nos Estados Unidos prevaleceu a "one-drop rule" [literalmente "regra de uma gota"], que tinha por objetivo evitar o contato entre as raças, considerado como fonte de degenerescência e perigo. A distância entre negros e brancos, mesmo depois da abolição da escravidão, era demarcada nos espaços públicos e privados através de uma série de leis anti-miscigenação. Assim, nos Estados Unidos prevaleceu um sistema racial binário, ideologicamente segregacionista e confrontante, que estabeleceu uma rigorosa linha de divisão entre as raças. ${ }^{10}$ Utilizando-se de uma linguagem de "pureza do sangue", acreditava-se que bastava ter uma gota de sangue de ascendência africana que o indivíduo se tornaria imediatamente negro.

\footnotetext{
${ }^{10}$ Isso não significa que não tenha havido relações inter-raciais ou uma população "misturada" nos Estados Unidos, mas denota a forma com que foram incorporadas dentro do sistema classificatório e ideológico estadunidense.
} 
No Brasil, por outro lado, a segregação não se constituiu numa política oficial de governo, e as classificações raciais seguiram um continuum de cor. Na formação de uma ideologia nacionalista, as teorias raciais europeias foram readaptadas no Brasil, cabendo às elites dominantes justificar a miscigenação de sua própria raça, enquanto epifenômeno da nação, em vista dos países considerados mais civilizados da Europa. Para tanto, abandonou-se a noção de degenerescência e passou-se a entender a miscigenação de forma positiva, como fonte de orgulho nacional. Não obstante, a miscigenação enquanto projeto nacional foi admitida apenas porque vista como condição necessária para se chegar ao tão desejado branqueamento da nação. ${ }^{11}$ Assim, miscigenação e branqueamento no Brasil nunca se constituíram em processos excludentes, e a identidade racial de um indivíduo dependeria de outros determinantes, principalmente, de sua posição na hierarquia de classe.

No entanto, como a literatura que compara o Brasil e os Estados Unidos tem apontado (Winant, 1994; Marx, 1998; Telles e Sue, 2009), as formações raciais dos dois países têm se transformado substancialmente nas últimas décadas. Nos Estados Unidos, as categorias raciais têm se tornado mais maleáveis, enquanto no Brasil estaria havendo uma crescente polarização entre brancos e negros, com o aumento dos movimentos $e$ consciência negra no país.

Como as imagens e discursos sobre Gisele Bündchen analisadas neste artigo podem nos ajudar a refletir sobre essas transformações?

Como recente literatura sobre relações raciais nos Estados Unidos tem argumentado, tem havido naquele país um aumento

\footnotetext{
${ }^{11}$ Esse desejo de branqueamento motivou políticas públicas de incentivo à imigração europeia no Brasil, fazendo com que ingressassem no país cerca de quatro milhões de estrangeiros, entre eles portugueses, alemães, italianos, árabes e japoneses, entre os anos de 1872 e 1949. Para estudo sobre políticas públicas que favoreceram o branqueamento da população brasileira na época conferir Lesser, 1999; Seyferth, 1995; Skidmore, 1989,1990; Hofbauer, 2006.
} 
no número de indivíduos que se consideram "multiraciais". ${ }^{12}$ Isso se deve, entre outros fatores, à chegada massiva de novos imigrantes, advindos principalmente de diversos lugares da Ásia e da América Latina, que teve início com as reformas imigratórias de 1960, e cresceu significativamente com a "re-estruturação" da economia global desde a década de $1980 .{ }^{13}$ De acordo com Lee e Bean (2004), esse novo fluxo de imigrantes não europeus, assim como o aumento no número de casamentos inter-raciais, tem feito com que a antiga configuração racial baseada na dicotomia entre brancos e negros tenha passado por profundas modificações naquele país.

Essa "multiracialidade" pode ser lida de diversas formas. Para alguns, o crescimento da população que se auto-identifica como "multiracial" é visto como sinônimo de um declínio do racismo e da raça enquanto definição categórica de identidades individuais e sociais. Outros, porém, munidos de observação empírica cuidadosa, argumentam que novas formas de racismo estão emergindo e que a própria definição de branquidade tem se alargado, na medida em que seletas minorias ou seletos membros de algumas minorias passam a ser incorporados no corpo da nação (Lee e Bean, 2004). Alguns estudos sugerem mesmo que os latinos e os asiáticos, assim como os irlandeses ou italianos antes deles, têm sistematicamente procurado se aproximar dos valores e ideais da branquidade, que passa, assim, a ser, cada vez mais, definida em termos transnacionais.

No entanto, como estudos empíricos também mostram, nem todos os latinos ou asiáticos são capazes de atravessar tais fronteiras raciais. A categoria "latino" (que mais particularmente nos interessa neste artigo) se constitui numa denominação

${ }^{12}$ Ver Lewis, 2004, Lee e Bean, 2004, McDermott e Samson, 2005.

${ }^{13}$ No ano de 2002, a estimativa era de que o número de pessoas nascidas no estrangeiro vivendo nos Estados Unidos excedesse 34.2 milhões, sendo que a população da segunda geração de imigrantes alcançaria a faixa de 31.5 milhões, de forma que os imigrantes e seus filhos totalizariam cerca de 66 milhões de pessoas, ou $23 \%$ da população daquele país (U.S. Bureau of Census 2002). 
inclusiva para uma população marcadamente diferenciada em termos de origem nacional e regional, classe social, gênero e raça, entre outras variáveis que definem o lugar do indivíduo na hierarquia social. Para alguns latinos, particularmente aqueles que se aproximam de ideais de branquidade europeus, sua origem nacional funciona mesmo como valor agregado para sua ascensão social. É neste contexto que o sucesso de Gisele Bündchen deve ser entendido. Para figuras como Gisele, é como se raça não se aplicasse, tornando-se ela apenas étnica, no sentido de poder ser assimilada à branquitude estadunidense, a exemplo dos grupos europeus, vistos apenas enquanto etnia incluída na categorial racial de branquidade. Nas representações da mídia estadunidense analisadas, a branquidade transnacional de Gisele é equacionada a características "globalizadas", tornando discursivamente universal e transparente aquilo que é valorizado dentro de uma configuração racial estadunidense que enfatiza o desaparecimento de "traços étnicos".

Tomando de empréstimo o conceito de "governamentabilidade" de Foucault para entender a incorporação diferenciada de grupos de imigrantes, a antropóloga Aihwa Ong (1996) chama a atenção de que projetos hegemônicos de disciplinamento de indivíduos dentro das normas aceitáveis de pertencimento nacional são realizados não apenas pelo apparatus estatal. Desenvolvendo o conceito de "cidadania cultural", Ong defende que o pertencimento nacional é definido por uma variedade de práticas $e$ instituições cotidianas, para as quais a mídia é instrumental. De acordo com ela, a "administração da diversidade", ou a incorporação das diferenças no âmbito da nação, é feita através de estratégias como, por exemplo, a promoção de "minorias exemplares" (minority models). Tal estratégia implica a promoção de certos grupos minoritários (ou de certos corpos que fazem parte desses grupos), passíveis de se conformarem aos termos convencionais de "americanidade". Tal "americanidade", por sua vez, seria definida pela hegemonia da América branca e promovida como o "eu sem marcas" (unmarked 
self) da nação, contra o qual todos os "outros" são medidos e julgados. Ainda de acordo com Ong, a ascensão social das minorias, baseada na celebração dos mais caros valores norteamericanos, tais como neoliberalismo, consumismo $e$ individualismo, é inseparável do processo de "embranquecimento". Em nenhum outro lugar, a promoção de "minorias exemplares" e o processo de "embranquecimento" se tornam mais evidentes do que nos casos de "crossover celebrities", como Gisele, celebridades híbridas, ou, literalmente, celebridades que "atravessam fronteiras". Celebridades híbridas são membros de minorias que alcançaram estrelato público através da obliteração de marcas raciais (e a aceitação de certos traços "étnicos"), um feito apenas possível para alguns, mas que, no entanto, funciona a favor de uma perspectiva supostamente "color blind" ou indiferente às diferenças de cor. Tal ideologia "color blind" estaria mais próxima à ideologia de democracia racial, tal como definida no contexto brasileiro, de acordo com a qual raça seria vista como insignificante, haja vista a capacidade dos indivíduos de "passarem" de uma a outra categoria racial.

No Brasil, por outro lado, apesar da persistência da ideologia da democracia racial e da negação discursiva do racismo, estaria havendo uma crescente polarização das raças, devido, principalmente, ao aparecimento e consolidação de organizações de consciência negra (Telles e Sue, 2009). Tal polarização se faz notar principalmente nas discussões sobre ações afirmativas e cotas raciais para o ingresso da população afrodescendente nas universidades e no mercado de trabalho. $\mathrm{Na}$ batalha jurídica e simbólica que se trava nessas arenas, a consciência da desigualdade racial no país tem se ampliado e a categoria branca começa a aparecer sub-repticiamente, enquanto grupo a quem supostamente tem se usurpado vantagens $e$ privilégios. Porém, como argumentado desde o início deste artigo, falar sobre branquidade e racismo se constitui num desafio para aqueles que estudam relações raciais no Brasil, pois racismo no Brasil ainda continua sendo um tabu para aqueles segmentos 
privilegiados do país. No Brasil, acredita-se que não há discriminação, pois a população brasileira teria passado por um intenso processo de miscigenação, real ou simbólico, resultando na miríade de categorias intermediárias entre brancos e negros. Por isso, no Brasil, a própria categoria "branco" é frequentemente velada, e o que se tem é uma miríade de signos e sinais que fazem com que se perceba o outro diferencialmente.

Nesse sentido, a identidade e o lugar estrutural de branquidade são identificados por uma cadeia de associações discursivas ${ }^{14}$, em que ao branco é destinado todas as qualidades que denotam sucesso, felicidade, elegância e poder, entre outros atributos que os recobrem numa aura de transcendência e transparência.

Em nenhum lugar na pesquisa realizada na Veja sobre as representações de Gisele, a categoria branco é mencionada. No entanto, seus cabelos loiros e sedosos, seus olhos azuis e sua ascendência alemã nunca são esquecidos. Apesar do discurso oficialmente sancionado de que não há brancos no Brasil, pouco se fala de marcas de miscigenação quando se trata da nova "raça" de modelos, em sua maioria do sul do Brasil. A brancura como critério de estética social, a hiper-valorização do branco e tudo que a ele pode ser relacionado - da cor dos olhos, à textura dos cabelos, e a suposta elegância do andar -, fazem parte do senso comum, hegemonicamente associando a brancura à beleza $e$ poder. De fato, a linguagem da mistura não é sequer mencionada em relação a Gisele e outras modelos do Sul, sendo associada às "dançarinas de axé", não coincidentemente associadas à mulheres do nordeste do país, particularmente da Bahia, estado com o maior número de negros e "pardos" do país. Podemos mesmo pensar que como uma reação ao aumento da consciência negra,

\footnotetext{
${ }^{14}$ Conferir trabalho de Damasceno (2000) sobre como branquidade aparece nos anúncios de busca e oferta de emprego nos jornais dos anos 1940, e sobre as mudanças de linguagem e os eufemismos sob os quais a branquidade aparece, a partir do momento em que racismo se torna contravenção.
} 
não estaria havendo uma exacerbação de algo como uma consciência branca, mesmo que não nominada como tal.

Assim, a revista Veja representa e confere aporte ideológico a segmentos significativos das elites e classes médias emergentes que compartilham um projeto de civilidade identificado com a direita política e cultural, que tem a branquidade como modelo $e$ ideal a ser seguido. Por outro lado, num contexto transnacional, a brasilidade de Gisele é apresentada como uma espécie de branquidade aperfeiçoada nos trópicos (não necessariamente miscigenada), como defendida pela ideologia modernista freyriana. Geradora mesmo da modernidade nativa, tal "mito fundador" agrega valor à posição relativa das elites brasileiras na hierarquia das nações, enquanto o lugar de conforto e de extremo privilégio estrutural e simbólico da branquidade permanece ainda pouco interrogado.

\section{Considerações finais}

Pesquisas sobre a intersecção entre gênero, raça $e$ nacionalismo (Mosse, 1985; Parker et all, 1992) têm sistematicamente apontado para as formas com que o corpo tem sido utilizado como um símbolo da nação a fim de promover agendas nacionalistas. Como argumentado, os disciplinamentos da nação são realizados não apenas nas arenas políticas tradicionais, mas perpassam todas as esferas do cotidiano, delineando ideais de beleza, higiene, dieta e sexualidade. Através da promoção de certos corpos, o Estado e as diversas instituições sociais e políticas - inclusive a mídia - têm um papel fundamental em definir as formas através das quais hierarquias de raça, classe e gênero se tornam naturalizadas. O corpo é, ao mesmo tempo, um lócus onde se expressam ideais societários, e onde se expressam relações de poder e desejo. A exibição de corpos sexualizados enquanto espetáculos públicos revela um investimento erótico no romance nacional, um processo que tem sido característico ao longo da história do Brasil enquanto nação. 
Em seu papel de ícone, Gisele incorpora todas as ambivalências presentes na indústria publicitária. Como um ícone de brasilidade, ela não deve necessariamente ser representativa da típica mulher brasileira. Pelo contrário, um ícone deve representar um ideal, embora pleno de potenciais ambiguidades. A complexidade de seu corpo é resultante do espaço transnacional que ocupa, e em que diferentes projetos nacionais intersectam. A capacidade de circulação transnacional da mídia faz com que as mensagens expressas através de seu corpo se tornem significativas para os sistemas de representações sobre raça, nação e gênero, tanto nos Estados Unidos, quanto no Brasil.

Nos Estados Unidos, as representações do corpo de Gisele promovem uma obliteração pan-étnica das diferenças culturais, ao mesmo tempo em que se baseiam em tipos raciais historicamente construídos e passíveis de serem reconhecidos por uma audiência transnacional. Suas imagens estão imbuídas de uma economia erótica que promove o exótico, ainda que numa versão contida, que promove uma brasilidade, possivelmente a latinidade, moderada e embranquecida, reafirmando o ideal imaginário de relação entre nações. Gisele Bündchen representaria, assim, o símbolo e evocação de um ideal de beleza universal, capaz de transcender divisões nacionais, étnicas e raciais. O sucesso de Gisele carrega consigo a mensagem não tão implícita de que estilo de vida, moda e bom-gosto transcendem raça e etnicidade, no âmbito da ideologia "color blind" estadunidense, que se aproxima da ideologia de democracia racial, tal como concebido no contexto brasileiro. No Brasil, por sua vez, ressalta-se, invariavelmente, a sua ascendência alemã, o que aponta para o fato de que não se trata de uma brasileira "típica", ou tal como aparece nos discursos oficiais que valorizam a mistura como ideologia nacional. É como se parcelas significativas das elites brasileiras, aquelas a que a Veja informa e dá voz, apresentassem para o mundo um novo padrão de beleza nacional, aquele só alcançável por uma nova "raça", representada por Gisele, o padrão há tanto almejado pelas elites brasileiras, e que as 
Identificando a branquidade inominada

colocaria numa relação de relativa igualdade com outras elites definidas em espaços transnacionais. Apresentada como um ícone nacional, as imagens de Gisele - que aparecem incansavelmente na mídia brasileira -, promovem um ideal de beleza que favorece um ideal de embranquecimento que ainda persiste largamente na sociedade brasileira.

\section{Referências bibliográficas}

ASHLEY, Doanne, e Bonilla-SiLvA, Eduardo (eds.) White Out: The Continuing Significance of Racism. New York, Routlege, 2003.

BORDO, Susan. Unbearable Weight: Western Culture and the Body. Berkeley/London, University of California Press, 1993.

BrodKIN, Carol. How Jews Became White Folks and What That Says About Race in America. New Brunswick, N.J., Rutgers University Press, 1998.

CAROne, Iray e Bento, Maria Aparecida (orgs.). Psicologia Social do Racismo: Estudos sobre Branquidade e Branqueamento no Brasil. Petrópolis, Editora Vozes, 2002.

DAMASCENO, Caetana Maria. Em casa de enforcado não se fala em corda: notas sobre a construção social da boa aparência no Brasil. In: GUIMARÃES, Antonio S. e HUNTLEY, Lynn (orgs.) Tirando a Máscara: Ensaios sobre o Racismo no Brasil. São Paulo, Paz e Terra, 2000.

D'AVILA, Arlene M. Latinos, Inc.: the marketing and making of a people. Berkeley, University California Press, 2001.

FRANKENBERG, Ruth. (org.) Displacing Whiteness. Durham, Duke University Press, 1997.

FRANKENBERG, Ruth. White Women, Race Matters. Minneapolis, University of Minnesota Press, 1995.

GILMAN, Sander L. Making the Body Beautiful: a cultural history of aesthetic surgery. Princeton, Princeton University Press, 1999.

Guimarães, Antonio S. e Huntley, Lynn. (orgs.) Tirando a Máscara: Ensaios sobre o Racismo no Brasil. São Paulo, Paz e Terra, 2000. 
Guimarães, Antonio Sérgio. Racismo e Anti-Rascismo no Brasil. São Paulo, Editora 34, 1999.

HofBAUER, Andreas. Uma História de Branqueamento ou o Negro em Questão. São Paulo, FAPESP, Ed. UNESP, 2006.

LEE, Jennifer e BEAN, Frank D. America's Changing Color Lines: Multiracial Identification. Annual Review of Sociology 30, 2004, pp.221-42.

LESSER, Jeffrey. Negotiating National Identity. Durham e Londres, Duke University Press, 1999.

LEWIS, Amanda. What Group? Studying Whites and Whiteness in the Era of Color-Blindness. Sociological Theory 22, 2004, pp.223-246.

LoCK, Margaret. Cultivating The Body: Anthropology and Epistemologies of Bodily Practice and Knowledge. Annual. Review of Anthropology 22, 1993, pp.133-55.

MACHADO-Borges, Tais. O Antes e o Depois: Feminilidade, Classe e Raça na Revista "Plástica e Beleza". Luso-Brazilian Review n 45, vol.1, 2008, pp.146-163.

MAIA, Suzana M. Transnational Desires. Nashville, Vanderbilt University Press, 2012.

- Brazilian Women Crossing Borders. In: AARON, Jane; AltniCK, Henrice and WeEdon, Chris. (orgs.) Gendering Border Studies. Cardiff, University of Wales Press, 2010, pp.63-82.

- Sedução e identidade nacional: dançarinas eróticas brasileiras no Queens, Nova York. Revista Estudos Feministas vol.17 n 3, Florianópolis, 2009a, pp.769-797.

. Intersections of the Transnational: Brazilian dancers in New York City's gentlemen's bars. Vibrant, vol.1, n6, 2009b, pp.37-64.

MARX, Anthony. Making Race and Nation: a Comparison of United States, South Africa and Brazil. Cambridge, Cambridge University Press, 1998.

MCCLINTOCK, Anne. Imperial Leather: race, gender, and sexuality in the colonial conquest. NY, Routledge, 1995. 
Identificando a branquidade inominada

MCDERMOTT, Monica e SAMSON, Frank L. White Racial and Ethnic Identity in the United States. Annual Review of Sociology 31, 2005, pp.245-61.

MOSSE, George. Nationalism and Sexuality: Respectability and Abnormal Sexuality in Modern Europe. NY, Howard Fertig, 1985.

ONG, Aihwa. Cultural Citizenship as Subject-Making: Immigrants Negotiate Racial and Cultural Boundaries in the United States. Current Anthropology 37, 1996, pp.737-62.

PARKER, Andrew; Russo, Mary; SOMmer, Doris; YeAger, Patricia. (eds.) Nationalism and Sexuality. NY, Routledge, 1992.

PARKER, Richard. Bodies, Pleasures and Passions: Sexual Culture in Contemporary Brazil. Boston, Beacon, 1991.

PIERUCCI, Antonio Flávio. As Bases Sociais da Direita: seus medos, seu dedo. In: PIERUCCI, A.F. Ciladas da Diferença. São Paulo, Editora 34, 1999, pp.58-86.

PINHO, Osmundo de Araújo. O efeito do sexo: políticas de raça, gênero e miscigenação. Cadernos Pagu (23), Campinas-SP, Núcleo de Estudos de Gênero - Pagu/Unicamp, 2004, pp.89-119.

PISCITElli, Adriana. Entre a Praia de Iracema e a União Europeia: turismo sexual internacional e migração feminina. In: PISCITELLI, Adriana; GREGORI, Maria Filomena; CARRARA, Sérgio. (orgs.) Sexualidades e saberes: convenções e fronteiras. Rio de Janeiro, Garamond Universitária, 2004, pp.250-270.

PIZA, Edith. Branco no Brasil? Ninguém sabe, niguém viu... In: GuimARÃES, Antonio S. e HunTLEY, Lynn. (orgs.) Tirando a Máscara: Ensaios sobre o Racismo no Brasil. São Paulo, Paz e Terra, 2000.

RAMOS, Artur Guerreiro. A Patologia do Branco Brasileiro. In: RAMOS, A. G. Introdução Crítica a Sociologia Brasileira. Rio de Janeiro, Ed. UFRJ, 1995 [1957].

RAmos, Silvia. Mídia e Racismo. Rio de Janeiro, Pallas, 2002.

RoEdiger, D. The Wages of Whiteness: Race and the Making of the American Working Class. Londres e Nova York, Verso, 1991. 
SchWARCZ, Lilia Moritz. O Espetáculo das Raças: Cientistas, Instituições e a Questão Racial no Brasil, 1870-1930. São Paulo, SP, Companhia das Letras, 1993.

SEYFERTH, Giralda. Construindo a Nação: hierarquias raciais e o papel do racismo na política de imigração e colonização. In: MAIO, Marcos Chor e SANTOS, Ricardo V. Raça, Ciência e Sociedade. Rio de Janeiro, Editora Fiocruz, 1995.

SKIDMORE, Thomas. Racial Ideas and Social Policy in Brazil, 1870-1940. In: GRAHAM, Richard. (ed.) The Idea of Race in Latin America, 18701940. Austin, University of Texas Press, 1990, pp.7-35.

. Preto no Branco: raça e nacionalidade no pensamento brasileiro. São Paulo, Editora Paz e Terra, 1989.

SOMMER, Doris. Irresistible Romance: the foundational fictions of Latin America. In: BHABHA, Homi (ed.) Nation and Narration. New York, Routledge, 1990, pp.71-98.

SovIK, Liv. "Aqui ninguém é branco": hegemonia branca e media no Brasil. In: WARE, Vron. (org.) Branquidade: identidade branca $e$ multiculturalismo. Rio de Janeiro, Garamond, 2004, pp.363-386.

STOLER, Ann Laura. Race and the Education of Desire: Foucault's History of Sexuality and the Colonial Order of Things. Durham, NC: Duke University Press, 1995.

STOLKE, Verena. O Enigma das Intersecções: classe, "raça", sexo, sexualidade. A formação dos impérios transatlânticos do século XVI ao XIX. Revista Estudos Feministas, n 14, 2006.

TELlES, Edward E. e SuE, Christina A. Race Mixture: Boundary Crossing in Comparative Perspective. Annual Review of Sociology 35, 2009, pp.129-46.

TWINE, Frances W. Racism in a Racial Democracy: The Maintenance of White Supremacy in Brazil. New Brunswick-NJ, Rutgers University Press, 1998.

WARE, Vron O poder duradouro da Branquidade: "um problema a solucionar. In: WARE, Vron. (org.) Branquidade: identidade branca e multiculturalismo. Rio de Janeiro, Garamond, 2004. 
Identificando a branquidade inominada

WINANT, Howard. Racial Conditions. Minneapolis, University of Minnesota Press, 1994.

\section{Artigos citados}

\section{Mídia estadunidense e transnacional:}

The Atlanta Journal-Constitution. "Unforgettable Faces: new models making their mark, redefining beauty style", Geórgia, Feb 27, 2000.

Boston Globe, by Nicole Veash, "A New Model for the Worldwide Look: Brazilians setting pace on Catwalks", Boston, Apr 16, 2000.

New York Times, by Jennifer Rich, "On Fashion's Catwalks: Milan, 7th Ave., Brazil", New York, Aug 1, 2000.

New York Times, by Guy Trebay, "The Season's Hottest Runway Accessory: her own nose", NY, Sep 12, 2000.

New York Times, by Larry Rother, "With Economy Brighter, Brazil's Leader Faces Wage Demands", New York, Nov 30, 2000.

Rolling Stone; by Kirk Gaard, "Hot Girl: Gisele", New York, Sep 14, 2000.

The Guardian, by Michael Ellison, "Thanks, I'm Off. So Gisele, the Brazilian Mannequin every Designer wants, has walked out on her agency", Manchester, Sep 23, 1999.

The Guardian, by Shane Watson, "Gisele, the fashion fantasy: on a babe too far", Manchester, Jan 28, 2000.

The Guardian, by Alex Bellos, "Style: Rio Bravo. Gisele's curves on the catwalks, bikinis that bare all, and cutting-edge design - Brazil is now the most fashionable place on the planet", Manchester, Jul 21, 2000.

The Times, by Deborah Brett, "Bombshell from Brazil explodes on to catwalks", London, Oct 2, 1999.

Vogue, "Gisele: Model of the Year",Dec 1999. 


\section{Mídia brasileira:}

Veja, por Ângela Pimenta "Pelé, Senna e agora Gisele: a história de sucesso da gaúcha de 19 anos que se tornou a mais requisitada modelo do milionário mundo da moda", 01 de dezembro de 1999.

Veja, por Rodrigo V. da Cunha, "As gaúchas são demais: Gisele, Alessandra, Jeisa e Shirley: como o Rio Grande do Sul se tornou uma máquina de produzir top models", 22 de março de 2000.

Veja, por Bel Moherdaui, "As Meninas do Brasil", 05 de julho de 2000.

Veja, por Daniela Pinheiro, "O que torna você sexy?", 21 de janeiro de 2004. 